\title{
Atmospheric self-cleaning coefficients as indicators of the atmospheric ability to dissipate pollutants in Ukraine
}

\author{
Liudmyla Malytska, Vira Balabukh \\ Ukrainian Hydrometeorological Institute of the Ministry on Emergencies of Ukraine and National Academy of Science \\ of Ukraine, 37 Nauky Ave., 03028, Kyiv-28,Ukraine, e-mail: m_alitsk_a@i.ua,balabukh_vira@ukr.net
}

\begin{abstract}
Air quality is determined by the level of air pollution, which depends on the concentration of pollutants and meteorological conditions conducive to their transport, dispersion and washout from the atmosphere. If emission variety is poor, the pollution level depends only on meteorological conditions. This article considers the atmospheric ability to dissipate pollutants in Ukraine, and the various features of this ability in different regions, through the comparative analysis of modifications of the atmosphere's self-cleaning index - the special mathematical formulas that formalize the influence of basic meteorological parameters on the content of impurities in the air.

In Ukraine, in accordance with the atmosphere self-cleaning coefficient $(K)$, meteorological conditions mostly lead to the dissipation of contaminants. But there are also allocated buffer zones, where meteorological conditions are favourable to a limited extent; it is very likely these areas will increase due to climate change. Based on analysis of the improved integrated meteorological index (UMPA), all territory of the country has steadily favourable conditions for the dissipation of pollutants, without limitedly favourable areas. The component analysis, however, showed that it is fully true only for the thermal component. Analysis of precipitation and wind coefficients has shown that the steppe zone has a sufficient, but unstable wetting, which ensures only partial opportunities for the atmosphere's self-cleaning and only a small part of Ukraine has good airing conditions. Taking into account the fact that results are not consistent and that the UMPA was developed for physical and geographical conditions of the north of the Russian Federation, we propose priority actions for adapting it for Ukraine.
\end{abstract}

Keywords: air quality, pollutant dissipation ability, self-cleaning coefficient, integrated meteorological index

Submitted 10 April 2017, revised 28 July 2017, accepted 30 October 2017

\section{Introduction}

Air pollution is one of the most important elements in the assessment of environmental comfort, and of what has a harmful effect on human health. Air pollution contributes up to $80-90 \%$ of the total carcinogenic and non-carcinogenic risk associated with exposure to contaminants and other environmental objects, according to scientific research (Bondar 2016). This is due mostly to the fact that pollutants from the air fall into different environments and are distributed almost everywhere. What a person consumes during the day, and generally in life, is much more in a volume ratio of air than it is for food and water. Today the risks to health from air pollution are beyond doubt, but qualitative data about the quantitative effects are still poorly defined.

Currently, the study of air pollution is carried out in two ways. The first way involves the direct measurement of the concentrations of pollutants, and the synthesis of data and information about the level of pollution (EEA 2002). The other way includes the study of meteorological conditions that affect the transfer and dispersion of pollut- ants and their washout from the atmosphere (Stepanenko et al. 2007).

In Ukraine and post-Soviet territory the potential of air pollution $(P P A)$ is the most widely-known index used to analyse the impact of meteorological conditions on the content of impurities in the air. It was developed in the A.I. Voeikov Main Geophysical Observatory (Bezuglaya 1980). PPA includes factors that contribute to the accumulation of impurities in the air, such as the frequency of surface temperature inversions, the frequency of calm (wind speed 0-1 m/s) and mist. But it does not account for meteorological factors affecting the dissipation of pollutants in the atmosphere. T.S. Selegay and his research team developed a method that describes the mechanism of accumulation and elimination of impurities from the atmosphere. It allows for the estimation of the meteorological and climatic potential of the atmosphere's dissipation ability $(A D A)$ (Selegay, Yurchenko 1990).

In Ukraine, despite a decline in production, the level of air pollution in large cities and industrial centres remains high. If emission variety is poor, the pollution level depends only on the meteorological conditions. 
That's why temporal changes in meteorological conditions caused by climate change strongly affect air quality and the comfort of human beings. The evaluation of the meteorological and climatic potential of the atmosphere's dissipation ability $(A D A)$ and its temporal changes is an important direction in atmospheric pollution research. This information allows the definition of regions most vulnerable to climate change and the development of adaptation measures.

The main task here is the study of $A D A$ potential in Ukraine, its regional features and changes throughout 1981-2010. The estimation of the atmosphere's dissipation ability is performed through analysis of the temporal variety of the atmosphere self-cleaning coefficients.

\section{Data and methods}

The atmosphere self-cleaning coefficient $(K)$ is calculated using the Lapina method (Lapina et al. 2008). This method takes into consideration factors both contributing to contaminant accumulation and dissipation in the atmosphere.

$$
K=\left(P_{3}+P_{4}\right) /\left(P_{1}+P_{2}\right)
$$

where: $P_{1}, P_{2}, P_{3}, P_{4}$ is the number of calm days (wind speed $0-1 \mathrm{mps}$ ), number of foggy days, number of days with total precipitation $\geq 0,5 \mathrm{~mm}$ and number of days with wind speed $\geq 6 \mathrm{mps}$ accordingly. This equation allows the calculation of the atmosphere self-cleaning ratio using the results of routine meteorological observations. We propose the amount of days with total precipitation $\geq 1 \mathrm{~mm}$ is taken into account, because most intense washout of contaminants from the atmosphere occurs when precipitation is $1-3 \mathrm{~mm}$ per day.

According to $K$ value, meteorological conditions are divided into five categories: $K>1,25$ - meteorological conditions lead to contaminant dissipation; $1,25 \geq K>0,8$ - meteorological conditions are limitedly favourable; $0,8 \geq K>0,4-$ meteorological conditions are limitedly adverse; $0,4 \geq K>0,2$ - meteorological conditions lead to contaminant accumulation; $K \leq 0,25$ - meteorological conditions are very unfavourable for the dispersion of pollutants.

So, the atmosphere self-cleaning coefficient reflects the ratio between frequency of conducive and non-conducive conditions. Averaged over long-term series, $K$ values describe $A D A$ climatic potential.

Also, air quality and the atmospheric ability to dissipate pollutants have been defined using the $A D A$ improved integrated meteorological index (UMPA) (Selegay 2014). It is designed on the basis of $A D A$ meteorological poten- tial, but this modification more fully reflects meteorological factors, primarily temperature and precipitation. The index is represented as the sum of three coefficients:

$$
\begin{gathered}
U M P A=K_{t}+K_{v}+K_{p r} \\
K_{t}=e^{0,176 t_{a v}} ; K_{v}=\frac{P_{\geq 6}}{P_{0-1}} ; K_{p r}=\frac{O_{p}}{400}
\end{gathered}
$$

where: $K_{t}, K_{v}, K_{p r}$ is the coefficient of temperature, wind and precipitation, respectively; $t_{a v}$ - the average annual temperature; $P_{\geq 6}-$ the number of days with wind speed $\geq 6$ mps per year; $P_{0-1}-$ the number of calm days (wind speed 0-1 mps) per year; $O_{p}$ - average annual precipitation.

For the mapping of environmental comfort, according to UMPA values, the authors propose the following boundary limits: $U M P A \geq 3,5$ - this is an area with favourable conditions for the dissipation of pollutants; $3,5<U M P A \geq 2,5-$ this is a buffer zone or area of risk, where positive or adverse meteorological conditions for atmosphere self-cleaning can be observed with equal probability; $U M P A<2,5$ - this is an area with conditions favourable for contaminant accumulation.

In this article the following terms have been used to indicate the assessed likelihood of an outcome or a result:

- virtually certain $99-100 \%$ probability $(p \leq 0,01)$;

- very likely $90-100 \%(0,1 \geq p>0,01)$;

- $\quad$ likely 66-100\% $(0,34 \geq p>0,1)$;

- about as likely as not 33-66\% (0,67 $\geq p>0,34)$;

- unlikely $0-33 \%(0,90 \geq p>0,67)$;

- very unlikely $0-10 \%(0,99 \geq p>0,9)$;

- exceptionally unlikely 0-1\% ( $p>0,99)$ (IPCC 2013).

The research was conducted for the period of 19812010 using daily data about temperature, wind speed, precipitation and fog from the 187 meteorological stations across Ukraine. Data was provided by the Central Geophysical Observatory (www.cgo.kiev.ua).

For spatial distribution (mapping) we used the Information and Reference System "Natural Elemental Meteorological Events in Ukraine", which was developed at the Ukrainian Hydrometeorological Institute, Department of Synoptic Meteorology (Balabukh et al. 2010).

\section{Results}

Atmosphere self-cleaning coefficient $(K)$

The analysis of climatic potential of the atmosphere's dissipation ability showed that in Ukraine conditions are mostly favourable for the atmosphere's self-cleaning. During 1981-2010 the annual average value of the selfcleaning coefficient varied between interval 0,95-1,47 and the long-term average value of $K$ was 1,2 (Fig. 1). 


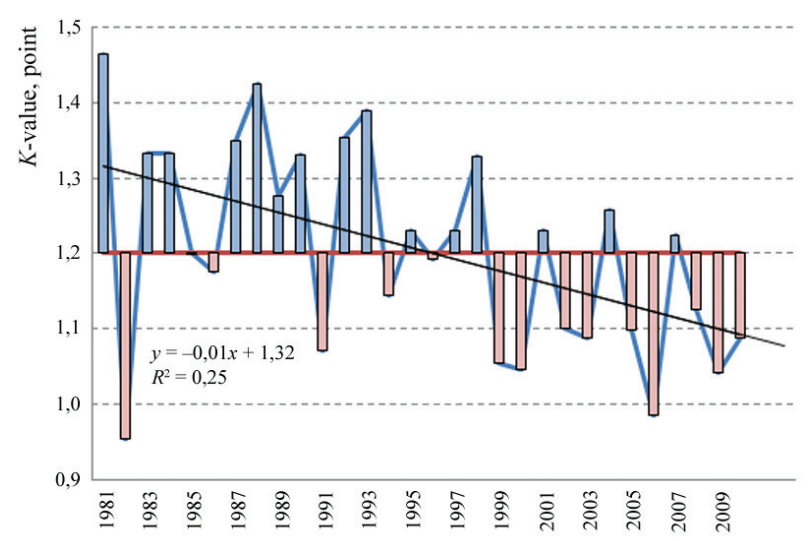

Fig. 1. Interannual variability of annual average coefficient value of $K$ (mean values for all stations)

The $A D A$ climatic potential has uneven spatial distribution (Fig. 2). The top meteorological conditions for the dissipation of pollutants in the atmosphere ( $K$ more than 2 points) are in the coastal areas (the Crimean Peninsula), southern parts of the Dnieper Upland, and the northeastern parts of the Volyn Upland. Limitedly favourable areas for the dissipation of pollutants are western parts of the Ukrainian Carpathians, the Donetsk ridge, and southwestern parts of the Dnieper Upland.

Since the beginning of the $21^{\text {st }}$ century it's virtually certain that the self-cleaning coefficient has had a decreasing tendency. The rate of change was 0,1 points per 10 years, generally, for Ukraine. However, there were highlighted territories where these changes are insignificant or have a different direction (Tab. 1). According to the results of statistical probability analysis, it's very likely that the atmosphere's self-cleaning ability is improving in Sumy and Kharkiv regions, by 0,2 and 0,14 points per 10 years, respectively. Such changes are likely to be occurring in Poltava and Mykolaiv regions too. Significant reduc- tions of ADA climatic potential $(p \leq 0,34)$ are observed in Volyn, Lviv, Rivne, Zakarpattia, Zhytomyr, Vinnytsia and Kherson regions. The rest of the Ukrainian territory does not have statistically significant changes.

\section{ADA improved integrated meteorological index (UMPA)}

The environmental comfort mapping, according to $U M P A$ values, has revealed that throughout the country there are steadily favourable conditions for the dispersion of pollutants $(U M P A \geq 3,5)$. The zones of risk or areas with favourable conditions for contaminant accumulation are not highlighted. Figures 3 and 4 show the spatial distribution of UMPA and its components throughout the territory of Ukraine.

In Ukraine the long-term average values fluctuate from 6 to 18 points (Fig. 3). This corresponds to extremely favourable conditions for the dissipation of pollutants. However, the index consists of three components.

The analysis of UMPA components has shown that the values of the temperature coefficient are $500 \%$ greater than others. The rain and wind coefficients have approximately the same dimensionality (Fig. 4). Such high values are due to significant positive average annual temperatures throughout the country. In the current climatic period (1981-2010), the field of average annual temperature in Ukraine maintains a zonal distribution of isotherms, complicated by the influence of Crimea and the Carpathian mountainous. Temperature values gradually increase from north to south in the range of $+7^{\circ} \mathrm{C}$ to $+11^{\circ} \mathrm{C}$, respectively. In mountainous areas, there is a natural decrease in temperature caused by physical and geographical conditions (Fig. 5).

The average annual isotherms basically match the positions of thermal coefficient isolines (Fig. 5). Despite that,

Table 1. The coefficients of linear trends and their assessed likelihood in Ukrainian regions (1981-2010)

\begin{tabular}{|l|c|c|l|c|c|}
\hline Region & $\begin{array}{c}\text { Coefficient of trend } \\
\text { (points per 10 years) }\end{array}$ & $\begin{array}{c}\text { Probability } \\
\text { (p-value) }\end{array}$ & Region & $\begin{array}{c}\text { Coefficient of trend } \\
\text { (points per 10 years) }\end{array}$ & $\begin{array}{c}\text { Probability } \\
\text { (p-value) }\end{array}$ \\
\hline Crimea & $-0,08$ & 0,295059 & Odessa & $-0,11$ & 0,217397 \\
\hline Volyn & $-0,40$ & 0,005671 & Poltava & 0,19 & 0,141646 \\
\hline Vinnytsia & $-0,11$ & 0,020273 & Rivne & $-0,82$ & 0,000014 \\
\hline Dnipro & $-0,12$ & 0,101749 & Sumy & 0,20 & 0,022541 \\
\hline Donetsk & $-0,08$ & 0,192298 & Ternopil & $-0,11$ & 0,328095 \\
\hline Zhytomyr & $-0,24$ & 0,020040 & Kharkiv & 0,14 & 0,063207 \\
\hline Zakarpattia & $-0,03$ & 0,081004 & Kherson & $-0,23$ & 0,034488 \\
\hline Zaporizhia & $-0,07$ & 0,225905 & Khmelnitsky & $-0,04$ & 0,762762 \\
\hline Kyiv & $-0,13$ & 0,114446 & Cherkassy & $-0,34$ & 0,000087 \\
\hline Kropivnitsky & $-0,06$ & 0,355174 & Chernivtsi & $-0,08$ & 0,191830 \\
\hline Lugansk & $-0,02$ & 0,828923 & Chernihiv & $-0,05$ & 0,452604 \\
\hline Lviv & $-0,19$ & 0,003859 & Ivano-Frankivsk & $-0,08$ & 0,432365 \\
\hline Mykolaiv & 0,14 & 0,231404 & Ukraine & $-\mathbf{0 , 1 0}$ & $\mathbf{0 , 0 0 4 6 6 6}$ \\
\hline
\end{tabular}




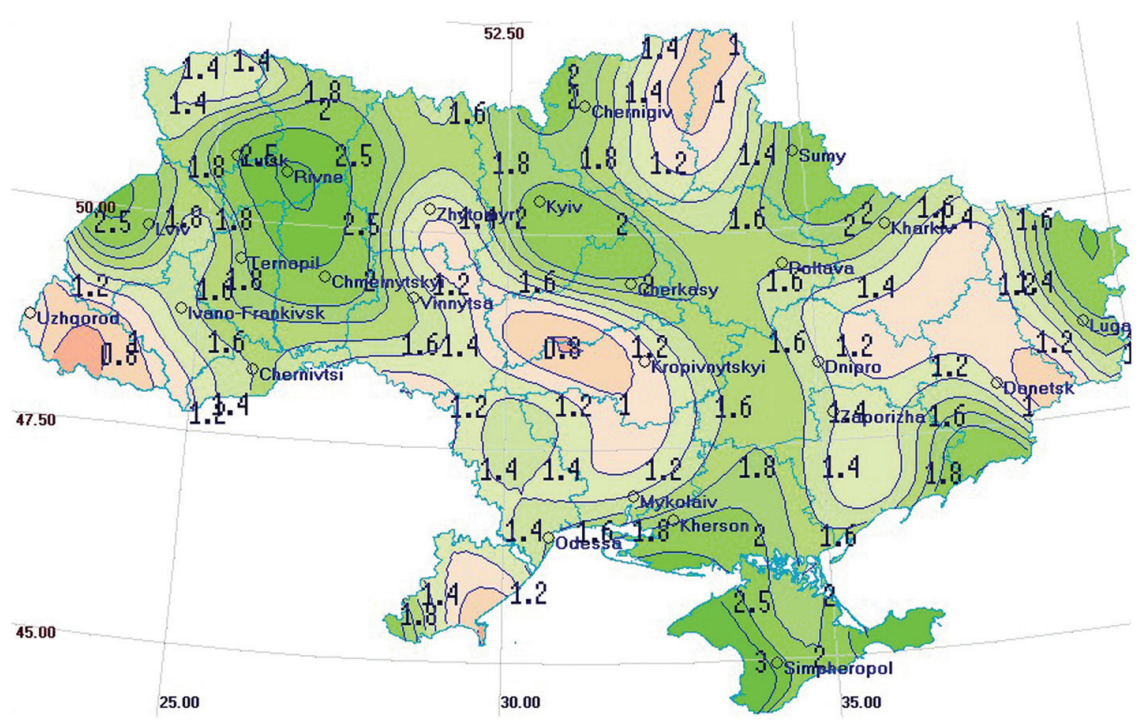

Fig. 2. The spatial distribution of the long-term average value of $K$ (1981-2010)

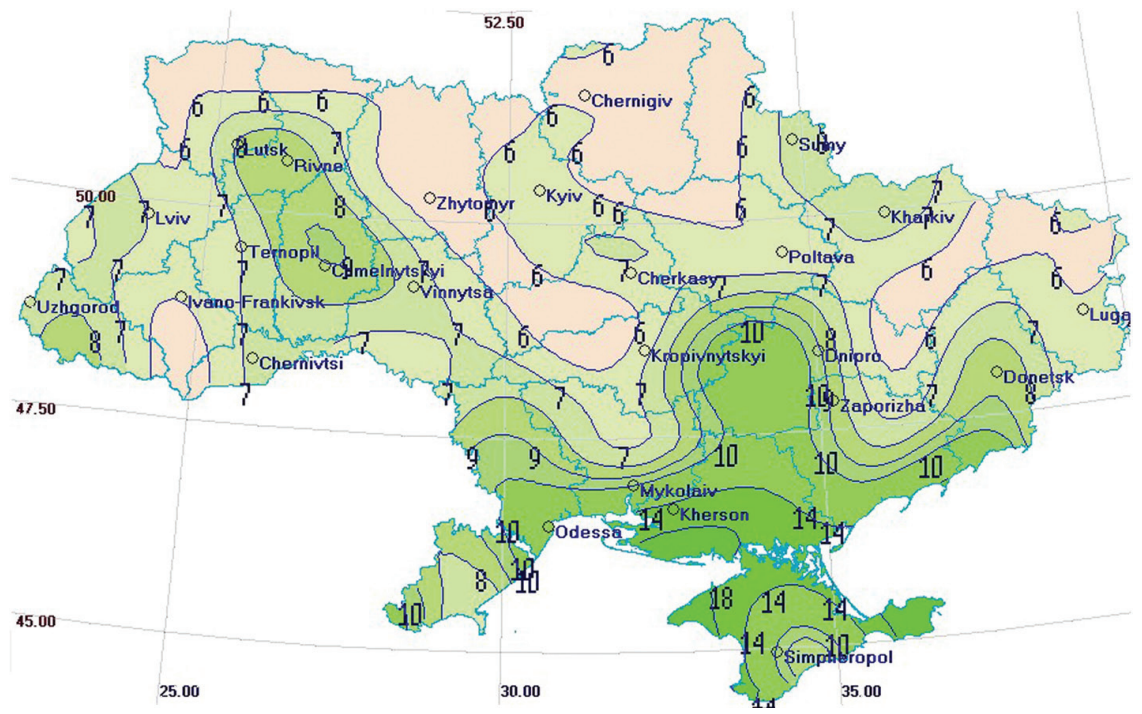

Fig. 3. The spatial distribution of long-term average value of UMPA (1981-2010)

all Ukrainian territory has extremely favourable thermal conditions for the dissipation of pollutants $\left(K_{t}>1\right)$. The southern areas have bigger $A D A$ potential than northern regions.

The precipitation coefficient has zonal distribution too. The main risk zone for this component is the southern area (steppe zone). It is the most arid territory of Ukraine. The annual precipitation varies between $380-550 \mathrm{~mm}$ per year. So, the area has a sufficient, but unstable wetting, which ensures partial opportunities for the atmosphere's self-cleaning.

The wind coefficient varies greatly: from 20,6 points in coastal areas to 0,001 in closed troughs of the Carpathians. This is due to a very heterogeneous wind regime. There is a mountain-valley circulation in the Carpathians, and breeze circulation in the coastal region and the calm zones. According to wind coefficient values, the area with good airing conditions occupies a small part of Ukraine (Fig. 4c).
Consequently, the UMPA value as the total index was such that it corresponded to extremely favourable conditions for the dissipation of pollutants. However, the component analysis showed that it is not fully true. This statement is also confirmed by its spatial distribution. The indicator was developed for the northern regions of the Russian Federation and it should be clarified for Ukraine. Since all coefficients included in the index have a wide variety of units, scale and spacing variation, we propose for the adaptation of UMPA for Ukraine, in order to make use of standardization, a linear transformation of characteristic values in such a way that they fall within a range comparable in magnitude (Jongman et al. 1995). The equation for the standardization of values is:

$$
\text { Std. } \text { score }=(\text { raw score }- \text { mean }) / \text { Std } \text {. deviation }
$$

The standardization procedure should be applied for each value of coefficients separately. The total sum, derived 

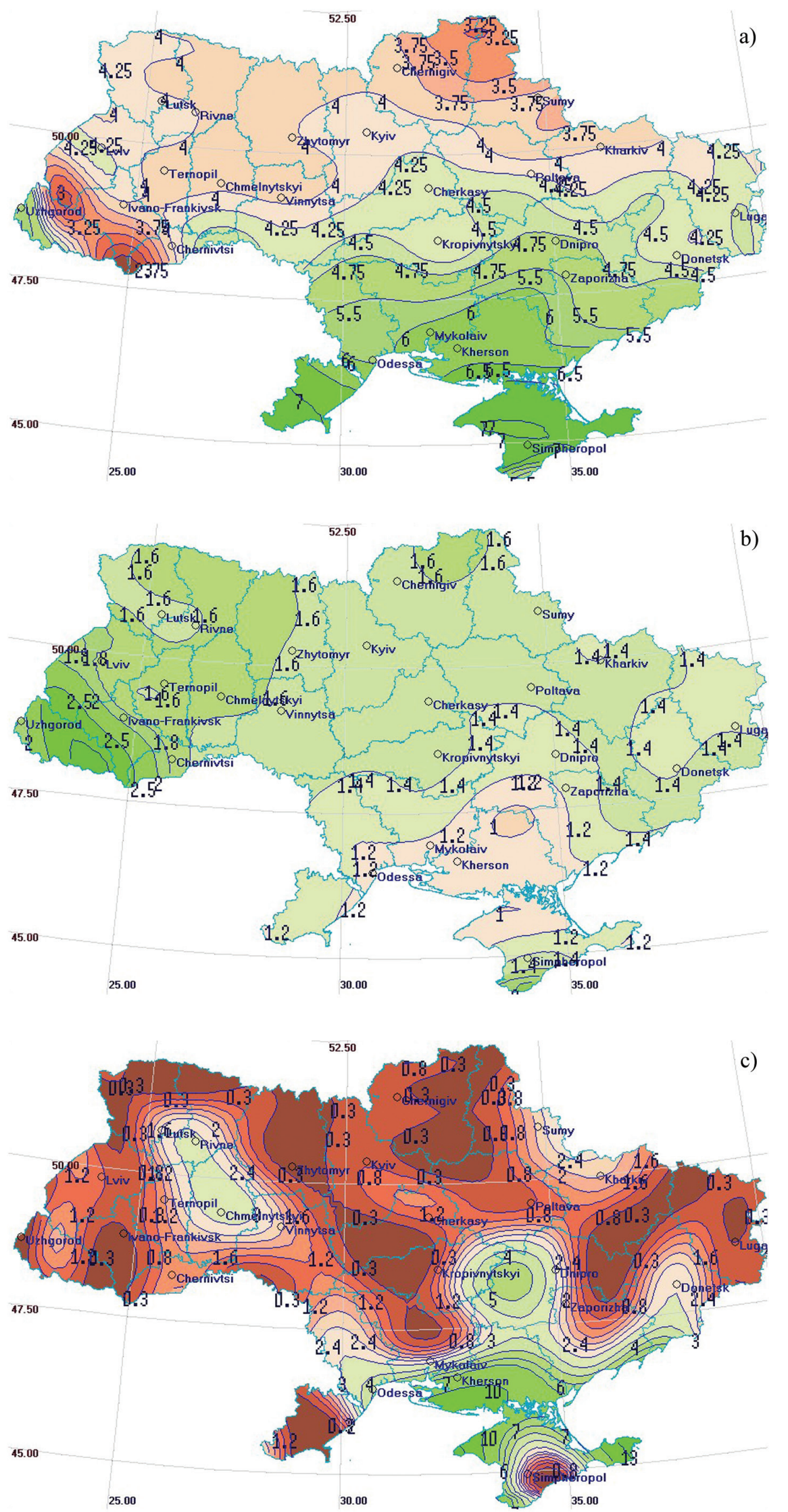

Fig. 4. The spatial distribution of UMPA components: a) thermal, b) precipitation c) wind

from the standardized coefficients, characterizes the $A D A$ climatic potential in Ukraine. Inasmuch as the relative contributions from each coefficient are not well determined, we did not impose weighting factors in equation 2.
The substantiation of the boundary conditions for the zoning is the 25 and 75 percentile of the sample. If standardized $U M P A \geq 0,38$, this is an area with favourable conditions for the dissipation of pollutants; 


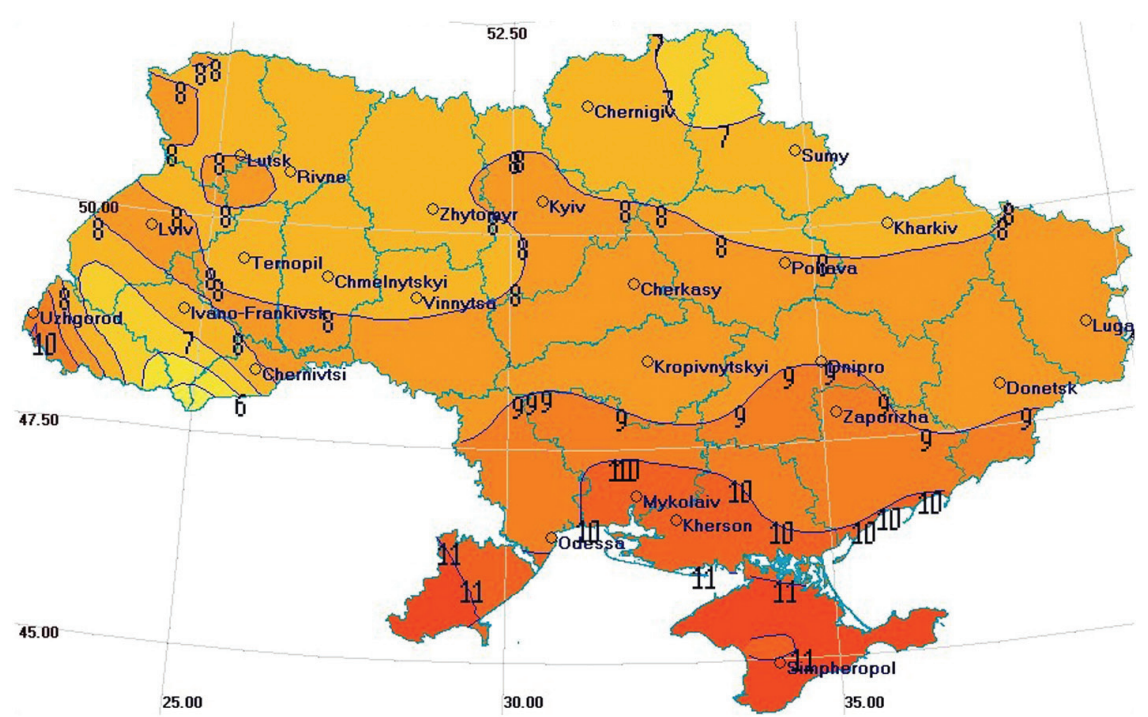

Fig. 5. The spatial distribution of average annual temperature (1981-2010)

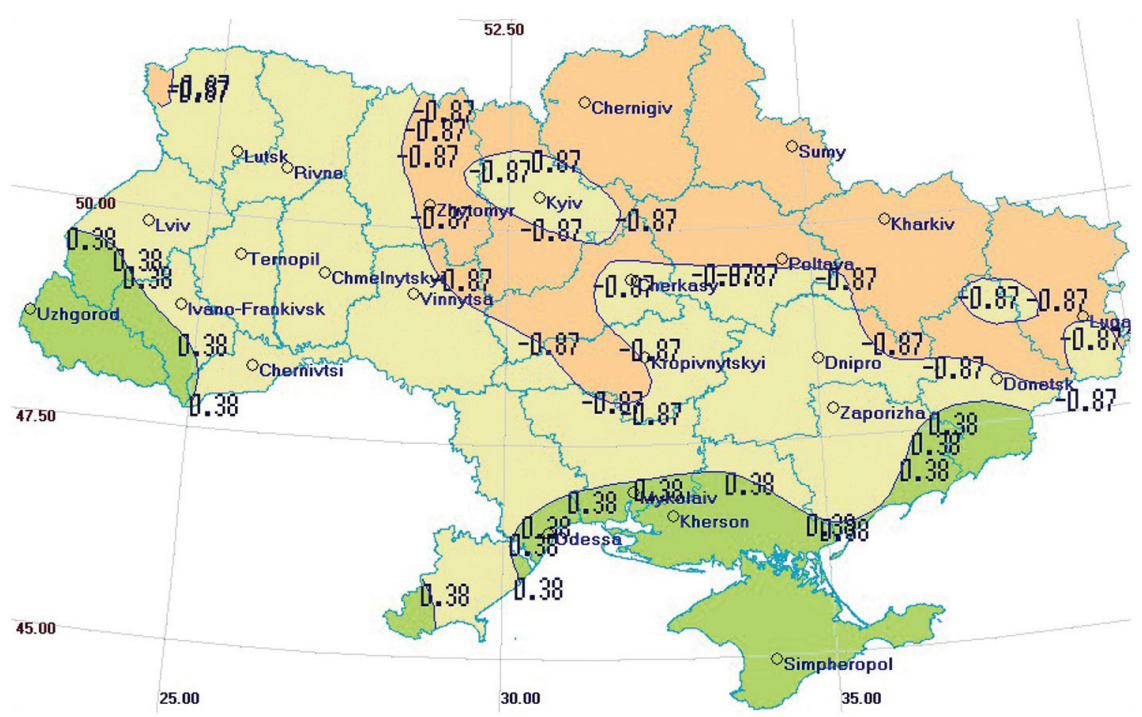

Fig. 6. The spatial distribution of standardized UMPA

$0,38<U M P A \geq-0,87$, this is a buffer zone or area of risk; $U M P A<-0,87$, this is an area with favourable conditions for contaminant accumulation.

The map (Fig. 6) has a clarifying nature and is submitted for discussion. The further application of standardized $U M P A$ is intended to be implemented into further research.

\section{Conclusions}

The conducted analysis has revealed that meteorological conditions in Ukraine are principally conducive for the atmosphere's self-cleaning. The spatial distribution of ADA climatic potential is uneven. Northern, southern and western regions, with the exception of Transcarpathia, have the most conducive conditions. Transcarpathia is a buffer zone. The analysis results of $K$ and UMPA are not consistent. The UMPA values are so high that all territory has steadily favourable conditions for the dissipation of pollutants, without limitedly favourable areas. So, taking into account a thermal amendment for the calculation of $A D A$ that corrects the atmosphere's self-cleaning potential: the weight of the temperature coefficient for Ukraine is so significant that it offsets the impact of wind and rain. For the estimation of the atmosphere's ecological condition we recommend the use of the $K$ or standardized UMPA.

Bibliography

Balabukh V.O., Yahodynets S.M., Lavrynenko O.M., Sotnyk T.L., Talerko N.D, 2010, Integrated information system of natural meteorological phenomena and processes that determine them, (in Ukrainian), International Conference Global and Regional Climate Changes, Kyiv, available at http://uhmi. org.ua/conf/climate_changes/presentation_pdf/poster_1/ Balabukh_IDS_system.pdf (data access 06.11.2017)

Bezuglaya E.M., 1980, Meteorological potential and climatic features of urban air pollution, (in Russian), Gidrometeoizdat, $184 \mathrm{pp}$. 
Bondar O.I., 2016, National Report on the State of Environment in Ukraine in 2014, (in Ukrainian), 350 pp., available at https://menr.gov.ua/files/docs/\%D0\%A3\%20 $2014 \% 20 \%$ D0\%A0\%D0\%9E\%D0\%A6\%D0\%86.pdf (data access 06.11.2017)

EEA, 2002, Air quality in the Phare countries 1997, Topic report 16/2001, European Environment Agency, Copenhagen, 73 pp. IPCC, 2013, Summary for Policymakers, [in:] Climate Change 2013: The Physical Science Basis. Contribution of Working Group I to the Fifth Assessment Report of the Intergovernmental Panel on Climate Change, T.F. Stocker, D. Qin, G.-K. Plattner, M. Tignor, S.K. Allen, J. Boschung, A. Nauels, Y. Xia, V. Bex and P.M. Midgley (eds.), Cambridge University Press, Cambridge, United Kingdom and New York, NY, USA, 28 pp.

Jongman R.H.G., ter Braak C.J.F., van Tongeren O.F.R, 1995, Data Analysis in Community and Landscape Ecology. Cambridge University Press, 324 pp.
Lapina S.N., Polyanskaya E.A., Fetisova L.M., Fetisova N.A., 2008, The atmosphere's self-cleaning ability of different districts of Saratov region, (in Russian), Proceedings of the Saratov University, Series: Earth sciences, 8 (2), 8-11

Selegay T.S., 2014, To develop an improved integrated meteorological index of atmosphere's dissipation ability (for example, the territory of Western Siberia): Report on research work, (in Russian), FSBI “SibNIGMI”, 132 pp.

Selegay T.S., Yurchenko I.P., 1990, Potential of the atmosphere's dissipation ability, (in Russian), Geography and Natural Resources, 2, 132-137

Stepanenko S.N., Ovchinnikova N.B., Voloshin V.G., Goncharenko N.N., 2007, The meteorological factor to dilute pollution as a parameter of potential pollution of the atmosphere, (in Russian), Ukr. hydrometeor. 2, 5-15 
